\title{
Hidrolisados protéicos de mucosa intestinal, levedura e proteína isolada de soja em dietas com leite em pó integral para leitões desmamados
}

\author{
Antonio João Scandolera ${ }^{1}$, Maria Cristina Thomaz ${ }^{2}$, Rodolfo Nascimento Kronka ${ }^{2}$, Fábio \\ Enrique Lemos Budiño ${ }^{1}$, Alessandro Luís Fraga ${ }^{1}$, Rizal Alcides Robles Huaynate ${ }^{1}$, Urbano dos \\ Santos Ruiz ${ }^{1}$, José Cristani ${ }^{1}$
}

\footnotetext{
1 Programa de Pós-Graduação em Zootecnia da FCAVIUNESP - Campus de Jaboticabal.

2 Departamento de Zootecnia - FCAVIUNESP - Campus de Jaboticabal.
}

RESUMO - Avaliou-se o efeito da substituição parcial do farelo de soja (FS) por hidrolisado protéico do conteúdo celular de levedura (HPCCL), proteína isolada de soja (PIS) ou hidrolisado protéico de mucosa intestinal de suínos (HPMIS) em dietas com leite em pó integral (LPI) sobre o desempenho, os níveis séricos de uréia e a incidência de diarréia em leitões desmamados. Foram utilizados 40 leitões desmamados aos 21 dias de idade (20 machos castrados e 20 fêmeas), distribuídos em delineamento em blocos ao acaso, com cinco tratamentos (dietas) e oito repetições. As dietas foram fornecidas em três fases, de acordo com a idade dos animais: fase pré-inicial 1 (21 aos 35 dias de idade): dieta à base de milho e farelo de soja (FS); dieta com 15,0\% LPI; dieta com 15,0\% LPI + 3,5\% HPMIS; dieta com 15,0\% LPI + 5,0\% de PIS; dieta com 15,0\% LPI + 5,0\% HPCCL. Na fase pré-inicial 2 (36 aos 49 dias de idade), foi mantida a dieta à base de milho e farelo de soja e o LPI foi reduzido para 7,5\% em todas as dietas, o HPMIS para 1,5\%, a PIS para 4\% e o HPCCL foi mantido em 5\%. Na fase inicial (50 aos 70 dias de idade), foi mantida a dieta à base de milho e farelo de soja, o LPI foi retirado de todas as dietas e os animais que nas fases pré-inicial 1 e 2 foram alimentados com as dietas contendo LPI e LPI + HPMIS passaram a ser alimentados com a dieta à base de milho e farelo de soja; a PIS foi reduzida para 3\% e o HPCCL para 2,5\%. No período de 21 a 35 dias, a dieta LPI + PIS proporcionou maior ganho diário de peso e melhor conversão alimentar. Nas fases seguintes, não houve diferença no desempenho entre as dietas. Até cinco dias após o desmame, os animais alimentados com as rações FS e LPI + PIS apresentaram menor índice de diarréia. Os níveis séricos de uréia não foram influenciados pelas dietas. A utilização de PIS, HPMIS e HPCCL em dietas complexas contendo leite em pó pode consistir em alternativa biologicamente viável em dietas para leitões.

Palavras-chave: conversão alimentar, diarréia, suínos, uréia

\section{Hydrolyzed proteins of intestinal mucosa membrane, yeast and isolated soybean protein in diets with dried whole milk to wealing pigs}

\begin{abstract}
The effect of partial replacement of soybean meal (SM) by hydrolyzed protein of the cellular content of yeast (HPCCY), isolated protein of soy (IPS), hydrolyzed protein of intestinal mucosa membrane of swine (HPIMS) in diets with dried whole milk (DWM) on performance, serum urea and diarrhea incidence of weaned pigs. Fourteen piglets weaned at 21 days old (20 barrows and 20 females), were allotted to a completely randomized experimental block design with five treatments (diets) and 8 replications each. The diets were fed in three phases according to the animal age. In the pre-initial phase 1 (21 to 35 days of age): corn-soy diet, diet with 15\% DWM, diet with 15\% DWM + 3,5\% HPIMS, diet with 15\% DWM + 5\% IPS, diet with 15\% DWM + 5\% HPCCY. In the phase pre-initial 2 (36 to 49 days of age) a corn-soy diet was maintained and DWM was reduced to $7.5 \%$ in all diets, HPIMS to $1.5 \%$; IPS to $4 \%$ and HPCCY was maintained in 5\%. In the phase initial (50 a 70 days of age) was maintained the corn-soybean based diet, DWM was removed of all the diets and the animals that received the treatments with DWM and DWM + HPIMS in the phases pre-initial 1 and 2, they were fed corn-soy diet, IPS was reduced to 3\% and HPCCY to 2.5\%. In the period from 21 to 35 days, the diet DWM + IPS provided the highest daily weight gain and better feed conversion. In the following phases, there was not difference in the performance among diets. Up to five days post weaning, pigs fed SM and DWM + IPS showed the lowest diarrhea incidence. The levels of serum urea were not influenced by the diets. The use of IPS, HPIMI and HPCCY in complex diets containing dried whole milk represents a viable biologically alternatives in diets for pigs.
\end{abstract}

Key Words: diarrhea, feed/gain ratio, swine, urea

Este artigo foi recebido em 18/1/2006 e aprovado em 8/10/2007. Correspondências devem ser enviadas para thomaz@fcav.unesp.br. 


\section{Introdução}

O período pós-desmame é a fase mais crítica no desenvolvimento dos suínos, principalmente porque neste período o sistema digestório está pouco adaptado para o aproveitamento de alimentos sólidos, diferentes do leite. Nesta fase, a composição da dieta dos leitões sofre grandes mudanças: o leite materno, que, antes era o principal fornecedor de nutrientes, é substituído por dietas sólidas que geralmente favorecem a ocorrência de diarréias (Spreeuwenberg et al., 2003).

Para proporcionar rápida transição neste período, são utilizados alimentos adequados à fase de desenvolvimento do sistema digestório dos leitões, como produtos lácteos, derivados sangüíneos, farinha de peixe, ovo em pó, subprodutos da soja. No entanto, o farelo de soja ainda é a principal fonte protéica de dietas para leitões, pois a baixa disponibilidade ou os elevados preços dos produtos alternativos limitam seu uso na alimentação animal.

O inconveniente da utilização de soja na alimentação de leitões está relacionado à presença de proteínas alergênicas, com propriedades que provocam reações de hipersensibilidade transitória na mucosa intestinal (Mendes et al., 2004) ocasionando alterações morfológicas e fisiológicas que afetam a absorção de nutrientes e prejudicam o desenvolvimento dos leitões.

Entretanto, com o processamento da soja, pela aplicação de elevada temperatura, pressão, pelo emprego de solventes orgânicos e até filtragens, muitos fatores alergênicos são eliminados resultando em produtos protéicos de elevada digestibilidade e valor nutricional para a alimentação animal (Soares et al., 2000).

Entre as fontes protéicas atualmente estudadas, o hidrolisado protéico de conteúdo celular de levedura (HPCCL) e o hidrolisado protéico de mucosa intestinal de suínos (HPMIS) foram desenvolvidos especificamente para utilização na alimentação de animais em condições críticas, como o desmame, pois, por se encontrarem na forma de hidrolisados, teriam sua absorção facilitada.

Neste estudo, avaliou-se o efeito da substituição parcial do farelo de soja (FS) por hidrolisado protéico do conteúdo celular de levedura (HPCCL), proteína isolada de soja (PIS) ou por hidrolisado protéico de mucosa intestinal de suínos (HPMIS), considerando as recomendações comerciais destes produtos, em dietas contendo leite em pó integral (LPI) sobre o desempenho, a ocorrência de diarréias e os níveis séricos de uréia em leitões após o desmame.

\section{Material e Métodos}

O experimento foi conduzido no Setor de Suinocultura do Departamento de Zootecnia da Faculdade de Ciências Agrárias e Veterinárias - UNESP, Campus de Jaboticabal, utilizando-se 40 leitões (20 machos castrados e 20 fêmeas) desmamados aos 21 dias de idade, com peso inicial de $5,98 \pm 1,1 \mathrm{~kg}$. Os animais foram alojados individualmente em baias de alvenaria equipadas com bebedouro tipo vaso comunicante e comedouro semi-automático, com acesso ad libitum à água e à ração.

Utilizou-se o delineamento em blocos ao acaso (para controlar diferenças iniciais de peso), com cinco tratamentos e oito repetições (quatro machos e quatro fêmeas), de modo que cada animal correspondeu a uma unidade experimental. Os tratamentos foram aplicados em três fases experimentais de acordo com a idade dos animais: fase pré-inicial 1 (entre 21 e 35 dias de idade): dieta à base de milho e farelo de soja (FS); dieta com 15,0\% de leite em pó integral (LPI); dieta com 15,0\% de leite em pó integral + 3,5\% de hidrolisado protéico de mucosa intestinal de suínos (HPMIS); dieta com 15,0\% de leite em pó integral $+5,0 \%$ de proteína isolada de soja (PIS); dieta com 15,0\% de leite em pó integral + 5,0\% de hidrolisado protéico de conteúdo celular de levedura (HPCCL).

Na fase pré-inicial 2 (entre 36 e 49 dias de idade), foram mantidos os mesmos grupos de animais em cada tratamento, porém, reduziu-se a quantidade de LPI para $7,5 \%$ em todas as dietas. O HPMIS foi reduzido para $1,5 \%$; a PIS foi para 4\% e o HPCCL foi mantido em $5 \%$.

$\mathrm{Na}$ fase inicial (entre 50 e 70 dias de idade), do mesmo modo que na fase anterior, mantiveram-se os mesmos grupos de animais em cada tratamento, porém, o LPI foi retirado de todas as dietas e os animais que nas fases préinicial 1 e 2 foram alimentados com as dietas LPI e LPI + HPMIS passaram a receber a dieta à base de milho e farelo de soja e foram identificados no experimento como FS/LPIf1e2 (referente à dieta LPI nas fases pré-inicial 1 e 2) e FS/LPI + HPMISf1e2 (referente à dieta LPI + HPMIS nas fases pré-inicial 1 e 2). As dietas com proteína isolada de soja e hidrolisado protéico de conteúdo celular de levedura permaneceram, porém, com a quantidade de PIS reduzida para 3\% e a quantidade de HPCCL reduzida para $2,5 \%$.

As quantidades de HPMIS, PIS e HPCCL adicionadas às dietas em cada fase seguiram as recomendações de uso comercial. As dietas foram formuladas considerando as composições dos ingredientes encontradas na base de dados do software SuperCrac 3.0 (TD Software Ltda - 
Viçosa/MG) e, para o HPMIS, PIS e HPCCL, utilizaram-se as composições fornecidas pelos fabricantes.

As dietas (Tabela 1) foram isonutritivas e isentas de qualquer produto com ação antidiarréica e devidamente suplementadas com minerais e vitaminas de forma a atender às exigências nutricionais dos leitões, considerando os níveis nutricionais preconizados pelo NRC (1998).

O ganho diário de peso (GDP), o consumo diário de ração (CDR) e a conversão alimentar (CA) foram avaliados considerando os valores de peso corporal e consumo de ração determinados ao início e ao final de cada fase. Na fase pré-inicial 1 (21 aos 35 dias de idade), o consumo de ração foi determinado diariamente por meio da pesagem das sobras de ração 24 horas após seu fornecimento. Posteriormente, foi realizado o cálculo do consumo médio diário nos períodos de 1 a 5,6 a 10 e 11 a 15 dias desta fase com a finalidade de auxiliar na compreensão da velocidade de aceitação das dietas pelos leitões e a incidência de diarréia durante esse período.

No estudo da incidência de diarréia na fase pré-inicial 1 , realizaram-se diariamente, às $7 \mathrm{~h} 30$ e às $17 \mathrm{~h} 30$, durante os 15 dias, a avaliação de escore fecal e a classificação das excretas em: escore 1 - fezes aquosas; escore 2 - fezes amolecidas, mas não fluidas (pastosa), e escore 3 - fezes

Tabela 1 - Composição em ingredientes e nutricional calculada das dietas experimentais fornecidas aos leitões durante as fases pré-inicial 1 (21 a 35 dias de idade) e 2 (36 a 49 dias de idade) e na fase inicial de crescimento (50 a 70 dias de idade)

\begin{tabular}{|c|c|c|c|c|c|c|c|c|c|c|c|c|c|}
\hline \multirow[t]{3}{*}{ Dieta } & \multicolumn{13}{|c|}{ Fase } \\
\hline & \multicolumn{5}{|c|}{21 a 35 dias de idade } & \multicolumn{5}{|c|}{36 a 49 dias de idade } & \multicolumn{3}{|c|}{50 a 70 dias de idade } \\
\hline & $\begin{array}{c}\text { LPI + } \\
\text { HPCCL }\end{array}$ & $\begin{array}{l}\text { LPI }+ \\
\text { PIS }\end{array}$ & $\begin{array}{c}\text { LPI + } \\
\text { HPMIS }\end{array}$ & LPI & $\mathrm{FS}^{\mathrm{f}}$ & $\begin{array}{c}\text { LPI + } \\
\text { HPCCL }\end{array}$ & $\begin{array}{l}\text { LPI + } \\
\text { PIS }\end{array}$ & $\begin{array}{c}\text { LPI + } \\
\text { HPMIS }\end{array}$ & LP I & $\mathrm{FS}^{\mathrm{f}}$ & HPCCL & PIS & $\mathrm{FS}^{\mathrm{f}}$ \\
\hline \multicolumn{14}{|l|}{ Ingrediente (\%) } \\
\hline Milho & 45,16 & 48,00 & 42,38 & 42,73 & 54,49 & 62,61 & 67,50 & 61,32 & 61,64 & 66,51 & 68,93 & 71,73 & 68,27 \\
\hline Farelo de soja & 24,93 & 19,80 & 27,10 & 30,87 & 37,28 & 21,36 & 17,80 & 25,49 & 26,95 & 29,67 & 23,10 & 19,26 & 26,00 \\
\hline Açúcar & 1,00 & 1,00 & 1,00 & 1,00 & 1,00 & - & - & - & - & - & - & - & - \\
\hline Calcário calcítico & 1,10 & - & 1,15 & 0,94 & 1,13 & 0,84 & 0,67 & 0,68 & 0,62 & 0,63 & 0,87 & 0,79 & 0,77 \\
\hline Fosfato bicálcico & 1,02 & 3,27 & 1,34 & 1,65 & 1,82 & 0,93 & 1,21 & 1,13 & 1,22 & 1,44 & 0,72 & 0,87 & 0,85 \\
\hline Óleo de soja & 3,00 & 3,00 & 3,00 & 3,00 & 3,00 & 0,60 & 0,60 & 0,60 & 0,60 & 0,60 & 2,00 & 2,00 & 2,00 \\
\hline DL-metionina (99\%) & 0,02 & 0,06 & 0,04 & 0,05 & 0,06 & 0,06 & 0,07 & 0,04 & 0,06 & 0,07 & 0,01 & 0,01 & 0,004 \\
\hline L-lisina $\mathrm{HCl}(78 \%)$ & 0,12 & 0,12 & 0,09 & 0,09 & 0,19 & 0,29 & 0,33 & 0,27 & 0,30 & 0,35 & 0,26 & 0,26 & 0,24 \\
\hline L-treonina (98\%) & - & - & - & - & 0,01 & 0,003 & 0,020 & 0,003 & 0,016 & 0,035 & - & 0,014 & - \\
\hline L-triptofano (98\%) & 0,015 & 0,01 & 0,015 & 0,01 & - & 0,002 & - & - & - & - & 0,013 & 0,011 & - \\
\hline $\begin{array}{l}\text { Suplemento } \\
\text { vitamínico e mineral }{ }^{\mathrm{a}}\end{array}$ & 0,10 & 0,10 & 0,10 & 0,10 & 0,10 & 0,10 & 0,10 & 0,10 & 0,10 & 0,10 & 0,10 & 0,10 & 0,10 \\
\hline Sal comum & 0,39 & 0,55 & - & 0,59 & 0,64 & 0,05 & 0,21 & - & 0,25 & 0,27 & 0,06 & 0,13 & 0,15 \\
\hline $\mathrm{HPCCL}^{\mathrm{b}}$ & 5,00 & - & - & - & - & 5,00 & - & - & - & - & 2,50 & - & - \\
\hline $\mathrm{PIS}^{\mathrm{c}}$ & - & 5,00 & - & - & - & - & 4,00 & - & - & - & - & 3,00 & - \\
\hline HPMIS $^{\mathrm{d}}$ & - & - & 3,50 & - & - & - & - & 1,50 & - & - & - & - & - \\
\hline $\mathrm{LPI}^{\mathrm{e}}$ & 15,00 & 15,00 & 15,00 & 15,00 & - & 7,50 & 7,50 & 7,50 & 7,50 & - & - & - & - \\
\hline BHT & 0,01 & 0,01 & 0,01 & 0,01 & 0,01 & 0,01 & 0,01 & 0,01 & 0,01 & 0,01 & 0,01 & 0,01 & 0,01 \\
\hline Inerte & 3,14 & 4,08 & 5,28 & 3,96 & 0,27 & 0,64 & - & 1,35 & 0,74 & 0,31 & 1,44 & 1,82 & 1,60 \\
\hline
\end{tabular}

Composição nutricional calculada

\begin{tabular}{lccc}
\hline & 21 a 35 dias de idade & 36 a 49 dias de idade & 50 a 70 dias de idade \\
\hline ED, kcal/kg & 3.400 & 3.400 & 3.400 \\
Proteína bruta (\%) & 22,00 & 20,00 & 18,00 \\
Lactose (\%) & 4,80 & 2,40 & 0,00 \\
Cálcio (\%) & 0,90 & 0,70 & 0,38 \\
P disponível (\%) & 0,40 & 1,28 & 0,26 \\
Lisina total (\%) & 1,35 & 0,36 & 1,10 \\
Metionina (\%) & 0,40 & 0,70 & 0,28 \\
Metionina + cistina (\%) & 0,76 & 0,79 & 0.58 \\
Treonina (\%) & 0,86 & 0,25 & 0,68 \\
Triptofano (\%) & 0,30 & 0,15 & 0,23 \\
Na (\%) & 0,20 & 0,10
\end{tabular}

a Suplemento vitamínico e mineral Frimix ${ }^{\circledR}$ Suinomix (Fri-Ribe) - Níveis de garantia por quilo do produto: vit. A - 4.000 .000 UI; vit. $\mathrm{D}_{3}$ - 220.000 UI; vit. E - $22.000 \mathrm{mg}$; vit. K - $500 \mathrm{mg}$; vit. $\mathrm{B}_{2}-3.750 \mathrm{mg}$; vit. $\mathrm{B}_{12}-20.000 \mathrm{mcg}$; pantotenato de cálcio - $12.000 \mathrm{mg} ;$ niacina - $20.000 \mathrm{mg} ;$ colina - $60.000 \mathrm{mg}$; I - $140 \mathrm{mg}$; Se - $30 \mathrm{mg}$, Mn -10.000 mg; Fe - $99.000 \mathrm{mg}$; antioxidante - $125 \mathrm{mg}$.

${ }^{b}$ Hidrolisado protéico do conteúdo celular de levedura - NuproTM - Alltech do Brasil.

c Proteína isolada de soja - Samprosoy FG 90 - Bunge Alimentos S.A.

d Hidrolisado protéico de mucosa intestinal de suíno - DPS 50 RD - Porsol ${ }^{\circledR}$ - Nutra-flo Company.

e Leite em pó integral.

f Dieta à base de milho e farelo de soja. 
firmes e normais. Considerou-se com diarréia o animal com fezes com escore 1 e 2 (Mores et al., 1990; Berto, 1997). Para análise, as observações foram tabuladas em três períodos de cinco dias e o percentual de incidência de diarréia foi estimado pelo somatório de vezes em que ocorreram os escores 1 e 2 sobre o total de observações registradas nos oito animais de cada dieta. Os resultados foram analisados pelo método qui-quadrado.

A uréia sérica foi medida aos 21, 35 e 49 dias de idade utilizando-se o kit comercial (Sistema Lab-Teste, Uréia UV Cinética) em amostras de sangue coletadas diretamente do seio oftálmico.

Os dados de desempenho em todas as fases e de uréia sérica aos 21, 35 e 49 dias de idade foram analisados pelo procedimento General Linear Model (GLM) do software estatístico Statistical Analysis System ${ }^{\circledR}$ (SAS, 1985) e as médias foram comparadas pelo teste Tukey (5\%).

\section{Resultados e Discussão}

Com base nos resultados de consumo diário de ração entre os dias 1 a 5, 6 a 10 e 11 a 15 dias da fase pré-inical 1 (Tabela 2), verificou-se que o consumo diário de ração não variou $(\mathrm{P}>0,05)$ entre as dietas, portanto, a velocidade de aceitação das dietas não foi influenciada pela presença de leite em pó integral ou qualquer outra fonte protéica nas concentrações testadas.

Durante os primeiros cinco dias, em geral, o consumo de ração foi muito baixo, o que está de acordo com a literatura, que relata consumo baixo ou nulo durante os primeiros dias pós-desmame (Bertol, 2000). Esses resultados corroboram os obtidos por Walker et al. (1986) e Hannas (2003), que também não observaram diferenças no consumo de ração nos primeiros 14 dias pós-desmame, quando os leitões foram alimentados com dietas contendo soja e fontes de proteína láctea.

A análise da incidência de diarréias durante os primeiros 15 dias pós-desmame (Tabela 3) evidenciou ocorrência de diarréia em todos os períodos. Durante o período de 1 a 5 dias, a incidência de diarréia foi menor $(\mathrm{P}<0,05)$ nos animais alimentados com a dieta FS, em comparação àqueles alimentados com as dietas LPI, LPI + HPMIS e LPI + HPCCL, que não diferiram apenas da dieta LPI + PIS. Esse resultado contraria a expectativa de que com essa dieta os animais sofressem mais com diarréia. No entanto, Decuypere et al. (1981) demonstraram que o processamento da proteína da soja, por elevar sua digestibilidade, reduz a incidência de distúrbios gastrointestinais.

No período de 6 a 10 dias após o desmame, apesar do aumento geral na incidência de diarréia, os animais alimen-
Tabela 2 - Consumo diário de ração (kg/dia) dos leitões nos períodos de 1 a 5, 6 a 10 e 11 a 15 dias da fase pré-inicial 1

\begin{tabular}{lccc}
\hline Dieta $^{1}$ & \multicolumn{3}{c}{ Idade (dias) } \\
\cline { 2 - 4 } & 1 a 5 & 6 a 10 & 11 a 15 \\
\hline Farelo de soja & 0,107 & 0,160 & 0,260 \\
$15 \%$ LPI & 0,113 & 0,172 & 0,277 \\
$15 \%$ LPI + 3,5\% HPMIS & 0,080 & 0,151 & 0,297 \\
$15 \%$ LPI + 5\% PIS & 0,116 & 0,159 & 0,317 \\
$15 \%$ LPI + 5\% HPCCL & 0,097 & 0,169 & 0,285 \\
P* & 0,200 & 0,723 & 0,619 \\
CV (\%)** & 31,48 & 20,35 & 26,10 \\
\hline
\end{tabular}

* Níveis de significância pelo teste $\mathrm{F} ;{ }^{*} \mathrm{CV} \%$ = coeficiente de variação

${ }^{1} \mathrm{LPI}$ - leite em pó integral; HPMIS - hidrolisado protéico de mucosa intestinal de suíno; PIS - proteína isolada de soja; HPCCL - hidrolisado protéico do conteúdo celular de levedura.

Tabela 3 - Incidência (\%) de diarréia nos leitões nos períodos de 1 a 5,6 a 10 e 11 a 15 dias da fase pré-inicial 1 (21 a 35 dias de idade)

\begin{tabular}{lccc}
\hline Dieta $^{1}$ & \multicolumn{3}{c}{ Incidência de diarréia (\%) } \\
\cline { 2 - 4 } & 1 a 5 dias & 6 a 10 dias & 11 a 15 dias \\
\hline Farelo de soja & $26 \mathrm{~b}$ & $53 \mathrm{~b}$ & $48 \mathrm{ab}$ \\
$15 \%$ LPI & $55 \mathrm{a}$ & $82 \mathrm{a}$ & $65 \mathrm{a}$ \\
$15 \%$ LPI + 3,5\% HPMIS & $50 \mathrm{a}$ & $51 \mathrm{~b}$ & $33 \mathrm{~b}$ \\
$15 \%$ LPI + 5\% PIS & $38 \mathrm{ab}$ & $54 \mathrm{~b}$ & $48 \mathrm{ab}$ \\
$15 \%$ LPI + 5\% HPCCL & $50 \mathrm{a}$ & $51 \mathrm{~b}$ & $40 \mathrm{~b}$ \\
Média & 43,8 & 58,2 & 46,8 \\
\hline
\end{tabular}

Médias com letras iguais na coluna não diferem entre si $(P>0,05)$ pelo teste $\chi^{2}$.

${ }^{1}$ LPI - leite em pó integral; HPMIS - hidrolisado protéico de mucosa intestinal de suíno; PIS - proteína isolada de soja; HPCCL - hidrolisado protéico do conteúdo celular de levedura.

tados com a dieta com 15\% de LPI apresentaram maior incidência de diarréia $(\mathrm{P}<0,05)$, que se manteve elevada inclusive no período seguinte (de 11 a 15 dias após o desmame), quando foi superior $(\mathrm{P}<0,05)$ à observada nos animais alimentados com as dietas LPI + HPMIS e LPI + HPCCL. A incidência de diarréia (Tabela 3) nos primeiros cinco dias pós-desmame não esteve relacionada ao CDR (Tabela 2), uma vez que os leitões alimentados com a dieta LPI + PIS tiveram a maior ingestão diária de ração $(0,116 \mathrm{~kg} /$ dia) mas não apresentaram a maior incidência de diarréia. Esse fato reforça a idéia de que o elevado consumo de ração na primeira semana pós-desmame não é o único responsável pela incidência de diarréia nesta fase.

Durante todo o período da fase pré-inicial 1 (Tabela 4), apesar de o consumo diário de ração ter sido similar $(\mathrm{P}>0,05)$, o ganho diário de peso e a conversão alimentar foram influenciados $(\mathrm{P}<0,05)$ pelas dietas.

Resultados semelhantes para o consumo de ração foram observados por Hannas (2003) em leitões dos 21 a 35 dias de idade alimentados com dietas contendo farelo de soja 
Tabela 4 - Desempenho dos leitões na fase pré-inicial 1 (21 a 35 dias)

\begin{tabular}{lccc}
\hline Dieta $^{1}$ & CDR (kg/dia) & GDP (kg/dia) & CA \\
\hline Farelo de soja & 0,170 & $0,077 \mathrm{~b}$ & $2,41 \mathrm{ab}$ \\
15\% LPIl & 0,188 & $0,074 \mathrm{~b}$ & $3,02 \mathrm{~b}$ \\
15\% LPI + 3,5\% HPMIS & 0,168 & $0,071 \mathrm{~b}$ & $2,56 \mathrm{ab}$ \\
15\% LPI + 5\% PIS & 0,197 & $0,119 \mathrm{a}$ & $1,73 \mathrm{a}$ \\
15\% LPI + 5\% HPCCL & 0,192 & $0,082 \mathrm{~b}$ & $2,48 \mathrm{ab}$ \\
$\mathrm{P} *$ & - & 0,006 & 0,04 \\
CV\%** & 16,86 & 30,26 & 28,47 \\
\hline
\end{tabular}

Médias na coluna seguidas de letras iguais não diferem $(P>0,05)$ entre si pelo teste Tukey.

* Níveis de significância pelo teste $\mathrm{F} ;{ }^{* \star} \mathrm{CV} \%$ = coeficiente de variação.

${ }^{1} \mathrm{LPI}$ - leite em pó integral; HPMIS - hidrolisado protéico de mucosa intestinal de suíno; PIS - proteína isolada de soja; HPCCL - hidrolisado protéico do conteúdo celular de levedura.

como única fonte de proteína (30\%) em comparação a dietas formuladas com apenas $18 \%$ de farelo de soja e contendo leite em pó, ovo integral e plasma suíno.

Nesta pesquisa, os animais alimentados com a dieta 15\%LPI + 5\%PIS apresentaram maior GDP e melhor CA em comparação àqueles alimentados com as demais dietas $(\mathrm{P}<0,05)$. Esses resultados podem estar relacionados à interação positiva LPI $\times$ PIS e ao melhor aproveitamento desses alimentos pelos leitões, uma vez que Kessler et al. (2001) observaram melhor qualidade da proteína isolada de soja, quanto à digestibilidade de matéria seca, proteína bruta, energia bruta e retenção protéica, em relação à proteína láctea e à proteína do farelo de soja.

O ganho diário de peso (GDP) e a conversão alimentar (CA) dos leitões alimentados com as dietas contendo LPI e PIS no período de 21 a 35 dias de idade foram significativamente $(\mathrm{P}<0,05)$ melhores, uma vez que a substituição do farelo de soja foi maior que nas demais dietas e proporcionou menor desafio dos fatores antinutricionais da soja, as proteínas alergênicas.

Os resultados obtidos para GDP e CA diferem dos observados por Li et al. (1991b), Friesen et al. (1993) e Soares et al. (2000), que registraram melhora no GDP e na CA dos animais alimentados com as dietas contendo leite em pó em relação àqueles alimentados com dietas contendo altos níveis de farelo de soja durante o período de 21 a 35 dias de idade.

Os valores de CDR, GDP e CA determinados nos animais alimentados com a dieta contendo 3,5\% de HPMIS foram inferiores aos obtidos por Ji (2002) em leitões desmamados aos 26 dias de idade e alimentados com dietas com mesmo nível de HPMIS. Esta diferença possivelmente está relacionada à genética e à idade ao desmame entre os dois estudos.

É provável ainda que a maior incidência de diarréia nos animais alimentados com a dieta LPI (Tabela 3) tenha afetado em maior intensidade a conversão alimentar desses animais durante toda a fase inicial 1 (Tabela 4), pois houve correlação positiva entre a incidência de diarréia e a conversão alimentar $(0,75)(\mathrm{Ji}, 2002)$. Embora estatisticamente a CA observada no grupo de animais alimentados com a dieta LPI tenha sido diferente apenas da observada com a dieta LPI + PIS, os valores foram numericamente 17,9 a $25,3 \%$ maiores que o obtido com as demais dietas. Esses resultados contrariam as conclusões feitas por Tokach et al. (1990) e Mahan \& Lepine (1991) de que a proteína do leite, por ser mais digestível que os carboidratos complexos e as proteínas de origem vegetal, previne os problemas digestivos possibilitando melhor desenvolvimento dos animais.

Durante a fase pré-inicial 2 (Tabela 5), não foram verificados efeitos $(\mathrm{P}>0,05)$ das dietas sobre o CDR, GDP e CA. De modo geral, a CA neste período foi melhor que a registrada no período de 21 a 35 dias de idade, o que pode estar relacionado à adaptação fisiológica dos animais às dietas e à sua recuperação quanto aos problemas de estresse pósdesmame (Li et al., 1991a,b).

O maior GPD e a melhor CA nos animais alimentados com a dieta 15\% de LPI + 5\% de PIS na fase pré-inicial 1 (21 a 35 dias de idade) não persistiram durante esse período (36 a 49 dias de idade). O CDR, o GDP e a CA verificados neste estudo nos leitões alimentados com dietas contendo $5 \%$ de HPCCL foram superiores aos observados por Maribo (2003) em leitões dos 28 aos 42 dias de idade alimentados com dietas contendo 5\% de HPCCL em substituição ao concentrado protéico de soja.

A análise dos resultados neste período revelou que não houve efeito $(\mathrm{P}>0,05)$ das dietas sobre o consumo diário de ração, o ganho de peso e a conversão alimentar (Tabela 6) nem favorecimento no desempenho dos leitões alimentados inicialmente com dietas adicionadas de fontes protéicas consideradas de alto valor biológico, tampouco daqueles que continuaram a receber essas fontes protéicas nesse período.

Tabela 5 - Desempenho dos leitões na fase pré-inicial 2 (36 a 49 dias)

\begin{tabular}{lccc}
\hline Dieta $^{1}$ & CDR (kg/dia) & GDP (kg/dia) & CA \\
\hline Farelo de soja & 0,438 & 0,293 & 1,74 \\
$7,5 \%$ LPI & 0,538 & 0,309 & 1,84 \\
$7,5 \%$ LPI + 1,5\% HPMIS & 0,569 & 0,356 & 1,65 \\
$7,5 \%$ LPI + 4\% PIS & 0,553 & 0,358 & 1,59 \\
$7,5 \%$ LPI + 5\% HPCCL & 0,488 & 0,337 & 1,46 \\
P* & 0,12 & 0,64 & 0,31 \\
CV\%** & 21,14 & 30,75 & 21,91 \\
\hline
\end{tabular}

Médias na coluna seguidas de letras iguais não diferem $(P>0,05)$ entre $s$ pelo teste Tukey.

*Níveis de significância pelo teste $\mathrm{F} ;{ }^{*} \mathrm{CV} \%=$ coeficiente de variação.

$1 \mathrm{LPI}$ - Leite em pó integral; HPMIS - Hidrolisado protéico de mucosa intestinal de suíno; PIS - Proteína isolada de soja; HPCCL - Hidrolisado protéico do conteúdo celular de levedura. 
Tabela 6 - Desempenho de leitões na fase inicial (50 a 70 dias)

\begin{tabular}{lccc}
\hline Dieta $^{1}$ & CDR $(\mathrm{kg})$ & GDP $(\mathrm{kg})$ & CA \\
\hline FS & 0,944 & 0,444 & 2,18 \\
FS/LPIf 1e2 & 1,039 & 0,453 & 2,38 \\
FS/LPI + HPMISf 1 e 2 & 0,987 & 0,454 & 2,18 \\
PIS3 & 1,021 & 0,478 & 2,17 \\
HPCCL2,5 & 0,950 & 0,429 & 2,22 \\
P* & 0,83 & 0,92 & 0,30 \\
CV\%** & 20,90 & 25,10 & 9,89 \\
\hline
\end{tabular}

1 FS (farelo de soja); FS/LPIf 1e 2 (dieta à base de farelo de soja e milho, com leite em pó integral - nas fases pré-inicial 1 e 2); FS/LPI+HPMISf 1e2 (dieta à base de farelo de soja e milho, com leite em pó integral +hidrolisado protéico mucosa intestinal suíno - nas fases pré-inicial 1 e 2); PIS3 (dieta com $3 \%$ de proteína isolada de soja); HPCCL2,5 (dieta com 2,5\% de hidrolisado protéico do conteúdo celular de levedura).

*Níveis de significância pelo teste $\mathrm{F}$; ${ }^{* *} \mathrm{CV} \%$ - coeficiente de variação. Médias na coluna seguidas de letras iguais não diferem $(P>0,05)$ pelo teste Tukey.

Resultados similares foram obtidos por Soares et al. (2000), que não verificaram diferença no desempenho de leitões dos 21 aos 56 dias de idade alimentados com rações com leite em pó ou proteínas processadas de soja dos 21 aos 35 dias de idade. Ao contrário, Carlson \& Veum (2000) verificaram melhora significativa no desempenho de leitões dos 20 aos 48 dias de idade alimentados com dietas contendo 5\% de plasma suíno ou 5\% de peptídeos de vegetais em relação aos leitões alimentados com dietas à base de milho e farelo de soja.

A ausência de diferença significativa no desempenho dos leitões durante esta fase pode estar relacionada ao fato de que, a partir dos 50 dias de idade, os animais estão aptos a digerir e aproveitar adequadamente os nutrientes de rações simples (à base de milho e farelo de soja), o que foi verificado por Katz et al. (1973), que relataram desempenhos similares entre leitões de 5 semanas de idade alimentados com dieta simples (milho + farelo de soja) ou complexa (milho + cevada + farelo de soja + farinha de peixe + soro de leite seco).

Os resultados observados neste estudo estão em acordo com os descritos por Alee (1985) de que as dietas complexas, formuladas com sucedâneos de leite e fontes protéicas mais elaboradas, poderiam ser ministradas a leitões desmamados aos 21 dias de idade por apenas mais 10 a 15 dias após o desmame sem prejuízo para o desempenho. Estão de acordo também com as recomendações de Tokach et al. (1999) de utilização de dietas fareladas à base de milho e farelo de soja adequadamente balanceadas com aminoácidos essenciais para leitões após os 42 ou 56 dias de idade. Confirmam ainda os resultados encontrados por Maribo (2001, 2003), que não verificaram efeito significativo no desenvolvimento de leitões na fase total de creche alimentados com dietas contendo 2,5\% e 5\% de HPCCL na
Tabela 7 - Concentração média de uréia sérica $(\mathrm{mg} / \mathrm{dL})$ determinada em amostras sangüíneas coletadas aos 21, 35 e 49 dias de idade

\begin{tabular}{lccc}
\hline Dieta $^{1}$ & \multicolumn{3}{c}{ Concentração } \\
\cline { 2 - 4 } & 21 & 35 & 49 \\
\hline Farelo de soja & 21,00 & 44,12 & 34,00 \\
LPI & 19,00 & 42,62 & 30,25 \\
LPI + HPMIS & 24,50 & 41,75 & 26,75 \\
LPI + PIS & 20,88 & 40,75 & 30,37 \\
LPI + HPCCL & 17,38 & 42,00 & 29,12 \\
P* & - & 0,937 & 0,346 \\
CV\%** & - & 18,64 & 22,84 \\
\hline
\end{tabular}

* Níveis de significância pelo teste $\mathrm{F} ;{ }^{*} \mathrm{CV} \%$ = coeficiente de variação

${ }^{1} \mathrm{LPI}$ - leite em pó integral; HPMIS - hidrolisado protéico de mucosa intestinal de suíno; PIS - proteína isolada de soja; HPCCL - hidrolisado protéico do conteúdo celular de levedura.

fase pré-inicial em substituição à soja tostada e ao concentrado protéico de soja.

Após o desmame, os níveis séricos de uréia (Tabela 7) aumentaram em relação ao dia do desmame (21 dias de idade). Esses resultados diferem dos obtidos por Jiang et al. (2000b), que verificaram diminuição significativa dos níveis de uréia plasmática com o aumento da idade. Não foi verificado efeito $(\mathrm{P}>0,05)$ das rações sobre os níveis de uréia aos 35 e 49 dias de idade.

Reduções significativas na uréia plasmática foram associadas por Jiang et al. (2000a,b) à maior eficiência alimentar. Essa associação não pôde ser confirmada neste experimento, uma vez que não foi possível correlacionar as melhores conversões alimentares das fases pré-inicial 1 e 2 aos menores níveis séricos de uréia verificados aos 35 e 49 dias de idade.

\section{Conclusões}

Em geral, os efeitos da utilização de hidrolisado protéico de mucosa intestinal de suínos, de hidrolisado protéico do conteúdo celular de levedura e de proteína isolada de soja em dietas complexas contendo leite em pó integral durante a fase de creche foram melhores ou similares aos obtidos com as dietas simples milho/farelo de soja e milho/farelo de soja + leite em pó integral, o que indica que a inclusão desses ingredientes em dietas contendo leite em pó integral para a fase pós-desmame pode ser uma alternativa biologicamente viável.

\section{Literatura Citada}

ALEE, G.L. Nutrition of the weaned pigs. In: NUTRITION CONFERENCE FOR FEED MANUFACTURERS, 1985, Maryland. Anais... Maryland: 1985. p.56. 
BERTO, D.A.; KRONKA, R.N.; THOMAZ, M.C. et al. Efeito do tipo de dieta e do sistema de alimentação na fase inicial sobre o desempenho de leitões. Revista Brasileira de Zootecnia, v.26, n.1, p.144-52, 1997.

BERTOL, T.M. Nutrição e alimentação dos leitões desmamados em programas convencionais e no desmame precoce. Concórdia: Embrapa Suínos e Aves, 2000. 44p.

CARLSON, M.S.; VEUM, T.L. Comparison between feeding peptide and plasma proteins on nursery pig growth performance and intestinal health. Springfield: University of Missouri, 2000. 3p.

DECUYPERE, J.A.; MEEUSEN, A.; HENDERICKX H.K. Influence of the partial replacement of milk protein by soybean protein isolates with different physical properties on the performance and nitrogen digestibility of early weaned pigs. Journal of Animal Science, v.53, n.4, p.1011-18, 1981.

FRIESEN, K.G.; GOODBAND, R.D.; NELSSEN, J.L. et al. The effect of pre and post weaning exposure to soybean meal on growth performance and on the immune response in the early weaned pigs. Journal of Animal Science, v.71, n.8, p.208998, 1993.

HANNAS, M.I. Plasma suíno e ovo inteiro desidratados em substituição a proteína bruta do leite em pó nas rações de leitões. Jaboticabal: Universidade Estadual Paulista, 2003. 149p. Tese (Doutorado em Zootecnia) - Universidade Estadual Paulista, 2003.

JI. Relatório sobre desempenho em teste de alimentação. Colombo: Nuvital, 2002. 2p. (Boletim Técnico, 32).

JIANG R.; CHANG, X.; STOLL, B. et al. Dietary plasma protein reduces small intestinal growth and lamina propria cell density in early-weaned pigs. Journal of Nutrition, v.130, p.21-26, 2000a.

JIANG, R.; CHANG, X.; STOLL, B. et al. Dietary plasma protein is used more efficiently than extruded soy protein for lean tissue growth in early-weaned pigs. Journal of Nutrition, v.130, p.2016-9, 2000b. Research Communication.

KATZ, R.S.; BAKER, D.H.; SASSE, C.E. et al. Efficacy of supplemental lysine, methionine and ralled oats for weaning pigs fed a law-protein corn-soybean meal diet. Journal of Animal Science, v.37, p.1165-68, 1973.

KESSLER, A.M.; SNIZEK JR., P.N.; RIBEIRO, A.M.L. et al. Avaliação da proteína isolada de soja (PIS) em dietas para leitões recém-desmamados. In: CONGRESSO BRASILEIRO DE VETERINÁRIOS ESPECIALISTAS EM SUÍNOS, 10., 2001, Porto Alegre. Anais... Porto Alegre: Associação Brasileira de Veterinários Especialistas em Suínos, 2001. p.295-296.

LEPINE, A.J.; MAHAN, D.C.; CHUNG, Y.K. Growth performance of weanling pigs fed corn-soybean meal diets with or without dried whey at various L-Lysine-HCl levels. Journal of Animal Science, v.69, n.5, p.2026-2036, 1991.

LI, D.F.; NELSSEN, J.L.; REDDY, P.G. et al. Measuring suitability of soybean products for early weaned pigs with immunological criteria. Journal of Animal Science, v.69, n.8, p.3299-307, 1991a.

LI, D.F.; NELSSEN, J.L.; REDDY, P.G. et al. Interrelationship between hypersensitivity to soybean proteins and growth performance in early weaned pigs. Journal of Animal Science, v.69, n.8, p.4062-9, 1991b.

MAHAN, D.C.; LEPINE A.J. Effect of pig weaning weight and associated nursery feeding programs on subsequent performance to 105 kilograms body weight. Journal of Animal Science, v.69, n.4, p.1370-8, 1991.

MARIBO, H. [2001]. Commercial products for weaners: NuPro 2000 as an alternative protein source for weaners. Report $n^{\circ}$ 526, The National Committee for Pig Production. Copenhagen. Disponível em: <http://www.danskeslagterier.dk/smcms/ LU_engelsk/Research_and_dev_lu/Research_Results_/ nutrition_Weanears/weanears_NuPro_2000/Index.htm? $\mathrm{ID}=591>$. Acesso em: 26/10/2002.

MARIBO, H. [2003]. Commercial products for weaners: NuPro 2000 as an alternative protein source for weaners. Report $\mathrm{n}^{\circ}$ 624, The National Committee for Pig Production. Copenhagen. Disponível em: <http://www.danskeslagterier.dk/ smcms/LU_engelsk/Research_and_dev_lu/Research_Results_/ Nutrition_Weanears/5792/Index.htm?ID=5792>. Acesso em: $17 / 1 / 2004$.

MENDES, W.S.; SILVA, I.J; FONTES, D.O. et al. Composição química e valor nutritivo da soja crua e submetida a diferentes processamentos térmicos para suínos em crescimento. Arquivo Brasileiro de Medicina Veterinária e Zootecnia, v.56, n.2, p.207-13, 2004.

MORES, N.; MARQUES, J.L.; SOBESTIANSKY, J. et al. Influência do nível protéico e/ou acidificação da dieta sobre a diarréia pós desmame em leitões causada por Escherichia coli. Pesquisa Veterinária Brasileira, v.10, n.3/4, p.85-8, 1990.

NATIONAL RESEARCH COUNCIL - NRC. Nutrient requirements of swine. 10.ed. Washington, D.C.: National Academic Science, 1998. 189p.

STATISTICAL ANALYSIS SYSTEM - SAS. SAS/STAT user's guide. Cary: 1985. 956p.

SOARES, J.L.; DONZELE, J.L.; OLIVEIRA, R.F.M. et al. Soja integral processada (fermentada e extrusada) e farelo de soja em substituição ao leite em pó em dieta de leitões desmamados aos 14 dias de idade. Revista Brasileira de Zootecnia, v.29, n.4, p.1153-61, 2000.

SPREEUWENBERG, M.A.M.; VERDONK, J.M.A.J.; VERSTEGEN, M.W.A. et al. Villus height and gut development in weaned piglets receiving diets containing either glucose, lactose or starch. British Journal of Nutrition, v.90, n.4, p.907-13, 2003.

TOKACH, M.D.; GOODBAND, R.D.; NELSSEN, J.L et al. Overall pig performance to market weight is improved by adding milk products, but no fat, to the starter diets. Journal of Animal Science, v.68, supl. 1, p.377. 1990.

TOKACH, M.D.; DRITZ, S.S.; GOODBAND, R.D. et al. Practical nutrition for the sew pig part 1: diet formulation. In: CONGRESSO BRASILEIRO DE VETERINÁRIOS ESPECIALISTAS EM SUÍnOS, 9., 1999, Belo Horizonte. Anais... Belo Horizonte: Associação Brasileira de Veterinários Especialistas em Suínos, 1999. p.71-78.

WALKER, W.R.; MAXWELL, C.V.; OWENS, F.N. et al. Milk versus soybean protein sources for pigs. I. Effects on performance and digestibility. Journal of Animal Science, v.63, p.505-12, 1986. 